\title{
A Model for Pain Self-Management of Patients with Haemophilia: Peer Education
}

\author{
Hua Zhao, Yu-Lin Guo, Ai-Rong Zhang, Rui-Hong Wu, Rui-Juan Zhang, Lin-Hua Yang \\ The Department of Hematology \\ The Second Hospital of Shanxi Medical University \\ Taiyuan, China \\ Zhi-Guang Duan* \\ Shanxi Medical University \\ Taiyuan, China \\ dzg528@yahoo.com.cn \\ *Corresponding author
}

\begin{abstract}
Hemophilia is a lifelong bleeding disorder with no cure. The pain, discomfort and risks that accompany hemophilia can be physically and emotionally stressful. Effective pain management is extremely important for improvement quality of life among patients with haemophilia. While some observational studies show a lack of readiness to change and a low adherence to recommended treatments in patients with haemophilia. The study found that a positive attitude and adherence can be enhanced if people have the opportunity to interact with peers who model and reinforce adherent behaviors. This paper reviewed current pain management strategies for patients with hemophilia and focus on peer education practical examples which have been used in many areas of health, and to find peer education models are well established as a means of self-management education to encourage the patients enhance the learning of pain self-management skills and improve emotional development. Future research in pain self-management of patients with haemophilia using peer education as a strategy should properly designed RCTs to demonstrate the efficacy of this intervention.
\end{abstract}

Key Words: haemophilia, chronic pain, pain self-management, peer education model

\section{HAEMOPHILIA AND CHRONIC PAIN}

Haemophilia is an X-linked congenital bleeding disorder caused by a deficiency of coagulation factor VIII (FVIII) (in haemophilia A) or factor IX (FIX) (in haemophilia B). A bleed into a joint can ca use acute, severe pain whereas the long-term effects of recurrent bleeds can lead to chronic and disabling symptoms [1-3]. Quality of life assessments identified pain occurs in $71 \%$ of patients with haemophilia and about $4 \%$ of patients with severe pain, and about $50 \%$ of haemophilia patients have more than one type of pain, in addition to joint pain. The older person with haemophilia who did not benefit from primary prophylaxis are particularly at risk for persistent pain in multiple target joints as a result of repeated joint bleeding with delayed treatment receive [4-9]. Besides being the leading cause of disability, chronic pain affects patients' overall quality of life including their ability to function and socialize, as well as impacting their family life [10]. Patients who are in chronic pain experience both physical and emotional distress.With these feelings comes decreased activity, low selfesteem, anxiety, irritability, and even increased pain, leading to serious dysfunction with the family and social life and other non-haemophilia-related health issues $[11,12]$.

\section{MANAGEMENT OF PAIN IN HAEMOPHILIA PATIENTS}

Now, there are no agreed-upon guidelines for pain management in haemophilia patients, and treatment is largely empirical. Treatment options of chronic pain vary widely, ranging from a number of pharmacologic therapies and non-pharmacologic treatments. Pharmacologic therapies may be part of a steppedcare progression from topical ana esthetics to mild analgesics to opioids. But another individuals who suffer from chronic pain may be reluctant to use analgesics.In one study, only $36 \%$ of haemophilia patients with pain were taking analgesics [13], and more patients expressed concerns about becoming dependent on and drug-related liver damage [14]. Non-pharmacologic therapy for pain management in haemophilia patients has been a mainstay of conservative treatment, include acupuncture, exercise, components of RICE, heat or cold treatments, hydrotherapy, massage and physical therapy. But great deal has been written both for and against these complementary therapies [15-21].In fact, chronic pain in patients with haemophilia may be a lifetime, the reduced quality of life are the long-term effects burdening to patients and their families. So, effective pain management is extremely important for improvement quality of life among patients with haemophilia. However,current numbers of healthcare providers are not sufficient to provide access to the increasing demand for primary care and many primary care practices have no one available to provide the timeconsuming counseling and teaching of management skills to relief the clinical signs $[22,23]$.Therefore several models are developed to promote pain self-management for haemophilics in chronic pain may be especially needed. While some observational studies show a lack of readiness to change and a typically low adherence to recommended treatments in patients with chronic pain [24-26]. Researchers believe that beliefs, attitudes, subjective norms, self-efficacy, and intentions in the manage- 
ment of pain to be the main reases for lack of adherence [2728]. This finding suggests that determining methods to improve adherence to recommended treatments is a necessary step to improving pain and functioning in this population.

\section{A Model For PAin MANAGEMEN:PeER EduCATION}

The study found that a positive attitude and adherence can be enhanced if people have the opportunity to interact with peers who model and reinforce adherent behaviors [17-29]. Dictionary defines peer as one that is of equal standing with another: one belonging to the same societal group especially based on age, grade, or status. Peer education is "the process whereby well-trained and motivated people undertake informal or organized educational activities with their peers" [30-32]. Peer education as a behavioural change strategy draws on several well-known behavioural theories. Such as in social learning theory, people change behavior by their individual values and self-esteem, while they have significant impacts on others [33].The theory of reasoned action states that one of the influential elements for behavioural change is an individual's perception of social norms or beliefs about what people who are important to the individual do or think about a particular behavior [34].To the diffusion of innovation theory, social influence plays an important role in behavior change, and the opinion leaders in a community or their society act as agents for behavior change, their influence on group norms or customs affect new behavior development [35].However, the theory of participatory education interprets empowerment and participation of the people affected by a given problem. Peers talk among themselves and determine a course of action, leading to the behavior change [36].According to historical records peer education can be traced back to Aristotle. There have been many peer education initiatives throughout history, working in a variety of contexts [37]. Soon after peer education was begun to prevent Asian influenza epidemic at Nebraska University in 1957 [38], it has been utilized in health projects seeking to reduce the incidence of smoking [39-43], substance misuse [4449], violence and promotion sexual health and prevention HIV among different age groups, especially in young men [50-57]. Today, as an important and effective method, peer education is implemented in protecting from cancer and early detection of it [58-65], providing adequate and balanced nutrition, controling blood glucose of diabetics to effect change at the individual level by modifying a person's knowledge, attitudes, beliefs, or behaviours [66-71]. Besides, it is used as well in the immigrant women to increase the level of physical activity [72].Current the power of peer education and social supports in control chronic pain has been confirmed [73,74]. Peer education which will provide sharing feelings and experiences by peers to other patiens with chronic pain to make living with chronic pain easier. Furthermore, the strategies help to promote pain selfmanagement in patients with chronic pain. Sandra and colleagues reported two randomized clinical trials in a Chronic Pain Self-Management Program (CPSMP), the research studies found that, on average, people who have participated in the peer support have more vitality or energy, less pain, less dependence on others, improved mental health, are more involved in everyday activities, and are more satisfied with their lives compared to those who have not taken the program.
Hemophilia is a lifelong bleeding disorder with no cure. The pain, discomfort and risks that accompany hemophilia can be physically and emotionally stressful. Education about safe pain management will help prevent undertreatment of pain and the resulting harmful effects. Many patients and doctors feel the best 'cure' is powerful medication, however it is important to realise that in many cases of chronic pain, medication alone may cause more problems than it solves. And while nondrug techniques pose minimal safety issues, the efficacy and safety of many of the non-pharmacologic approaches to pain management have not been demonstrated in randomized, controlled clinical trials. Peer education is to provide an environment to encourage the peer participants enhance the learning of pain self-management skills and promote growth of self-esteem, self reliance, emotional development, and creativity. Healthcare providers should recognize and understand the importance of peer-based behavioural strategies to improve patients with haemophilia effective pain self-management for these patients $[75,76]$. Now a longer-term (four months) study will determine whether use of peer mentorship to promote effective pain management in adolescent.The protocol for this new study has been approved by an independent ethics committee and is published in BioMed Central Public Health [77].A trial of a peer education intervention will be carried out in Shanxi haemophilia treatment center, through using trained haemophilics who have successfully learned pain management skills as peer educators, the educators will help all participants feel understood and cope with problems, enhance engagement in and adherence to chronic pain treatment programs. We hypothesize that haemophilics receiving the peer education intervention will report better to understand and cope with pain and improve overcome the harmful effects of stress skills, as compared to patients with haemophilia who do not receive the intervention.

\section{ACKNOWLEDGMENTS}

We would like to acknowledge the members of our study staff whose hard work made this study possible.

\section{REFERENCES}

[1] Choiniere M, Melzack R. Acute and chronic pain in hemophilia. Pain 1987;31:317-31.

[2] Llinás A.Haemophilic arthropathy. Haemophilia 2010 Jul;16(Suppl5):121.

[3] Rodriguez-Merchan EC. Musculoskeletal complications of hemophilia. HSSJ 2010 Feb : 6(1): 37-42.

[4] Gringeri A, Mantovani LG, Scalone L,Mannucci PM, COCIS Study Group. Cost of care and quality of life for patients with hemophilia complicated by inhibitors: the COCIS study group. Blood 2003; 102:2358-63.

[5] Elander J, Barry T. Analgesic use and pain coping among patients with haemophilia. Haemophilia 2003; 9: 202-13.

[6] Riley RR, Witkop M, Hellman E, Akins S.Assessment and management of pain in haemophilia patients. Haemophilia.2011;(17):839-845.

[7] Lambing A, Kohn-Converse B, Hanagavadi S, Varma V. Use of acupuncture in the management of chronic haemophilia pain.Haemophilia. 2012;18(4):613-7.

[8] Elander, J, Robinson, G, Mitchell, K, \& Morris, J. An assessment of the relative influence of pain coping, negative thoughts about pain, and pain acceptance on health-related quality of life among people with hemophilia. International Association for the Study of Pain. 2009; 145: $169-75$. 
[9] Kirsh, KL \& Fishman, SM. Multimodal approaches to optimize outcomes of chronic opioid therapy in the management of chronic pain. Pain Medicine 2011; Jan 12 Suppl:S1-11.

[10] Silva Zupančić Šalek, Ana Boban and Dražen Pulanić. Characteristics ofOlder Patient with Haemophilia. National Referral Haemophilia and Thrombophilia Centre, Division of Haematology Department of Internal Medicine, University Hospital Centre Zagreb Croatia Hemophilia,111130 .

[11] Hemophila Foundation Australia. The Pain Management Book for People with Hemophilia and Related Bleeding Disorders.Treatment of Hemophilia Monographs.No.22, WFH, Montreal,2000.

[12] J Elander, T Barry Analgesic use and pain coping among patients with haemophilia. Haemophilia9(2):202-13. 2003.

[13] van Genderen FR, Fischer K, Heijnen L et al. Pain and functional limitations in patients with severe haemophilia. Haemophilia 2006; 12: 147-53.

[14] Elander J, Barry T. Analgesic use and pain coping among patients with haemophilia. Haemophilia 2003; 9: 202-13.

[15] Rosted P, Jørgensen V. Acupuncture used in the management of pain due to arthropathy in a patient with haemophilia. Acupunct Med 2002; 20: $193-5$.

[16] Gomis M, Querol F, Gallach JE, Gonza'lez LM, Aznar JA. Exercise and sport in the treatment of haemophilic patients: a systematic review. Haemophilia 2009; 15: 43-54.

[17] Varni JW, Gilbert A. Self-regulation of chronic arthritic pain and longterm analgesic dependence in a haemophiliac. Rheumatol Rehabil 1982; 21: $171-4$

[18] Abraham J. Herbs: where is the harm? Br J Periop Nurs 2004; 9: 393400.

[19] Eslinger M. Hypnosis principles and applications: an adjunct to health care. Semin Periop Nurs 1998; 7: 39-40.

[20] Liu SX, Jiang L, Liang X et al. Study on graded therapy of hemophilic arthritis by integrative traditional Chinese and Western medicine. Chin $\mathrm{J}$ Integr Med 2007; 13: 301-5.

[21] Osiri M, Welch V, Brosseau L et al. Transcutaneous electrical nerve stimulation for knee osteoarthritis. Cochrane Database Syst Rev 2004; 4 : CD002823.

[22] Bodenheimer T, Pham HH. Primary care: current problems and proposed solutions. Health Aff (Millwood). 2010;29(5):799-805.

[23] Abram M, Nuzum R, Mika S, Lawlor G. Realizing Health Reform's Potential: How the Affordable Care Act Will Strengthen Primary Care and Benefi t Patients, Providers, and Payers. Vol 1. Publication 1466. New York, NY: Commonwealth Fund; 2011.

[24] Varni JW, La Greca AM, Spirto A. Cognitive-behavioral interventions for children with chronic health conditions. In Child and Adolescent Therapy: Cognitive-Behavioral Procedures. edited by: Kendall PC.NY:Guilford Press; 2000:291-310.

[25] Sharp TJ: Chronic pain: a reformulation of the cognitive-behavioural model. Behav Res Ther 2001, 39:787-800.

[26] S Zappa, M McDaniel, J Marandola, G Allen.Treatment trends for haemophilia A and haemophilia B in the United States: results from the 2010 practice patterns survey. Haemophilia 05/2012; 18(3):e140-53.

[27] Edwards HE, Nash RE, Yates PM, Walsh AM, Fentiman BJ, McDowell JK, Skerman. Improving pain management by nurses: a pilot peer intervention program. Nurs Health Sci. 2001 Mar;3(1):35-45.

[28] Allen LB, Tsao JC, Hayes LP, Zeltzer LK. Peer mentorship to promote effective pain management in adolescents: study protocol for a randomised controlled trial. Trials $01 / 2011 ; 12: 132$.

[29] Thienemann M, Martin J, Cregger B, Thompson HB, Dyer-Friedman J. Manual-Driven group cognitive-behavioral therapy for adolescents with obsessive-compulsive disorder: a pilot study. J Am Acad Child Adolesc Psychiatry. 2001;40:1254-1260.

[30] Bandura A.Social foundations of thought and action: a social cognitive theory.Englewood Cliffs, NJ, Prentice Hall, 1986.

[31] Bament, D. Peer education literature review, South Australian Community Health Research Unit, Adelaide, S.A.
[32] Bruyn M.D, Zielony R, Kimzeke G, and Stakic S. Peer education: Training of trainer manual. 1st edition. Published by UN Interagency Group on Young People Health Development and Protection in Europe and Central Asia; Sub-Committee on Peer Education.

[33] Bandura, A. Social Learning Theory. Prentice-Hall, Englewood Cliffs, NJ.

[34] Fishbein M, Ajzen I. Belief, attitude, intention and behaviour: an introduction to theory and research. Reading, MA, Addison-Wesley, 1975.

[35] Skinner TC, Cradock S, Arundel F, Graham W. Lifestyle and behavior: four theories and a philosophy: self-management education for individuals newly diagnosed with type 2 diabetes. Diabetes Spectr 2003;16:7580

[36] Freire P. Pedagogy of the oppressed. New York, Seabury Press, 1970.

[37] Rogers E. Diffusion of innovations. New York, Free Press, 1983. Wagner, L. Peer Teaching: Historical Perspectives. Greenwood, Westport, CT.

[38] Maurer F. A peer education model for teaching breast self-examination to undergraduate college women. Cancer Nursing, 20, 49-61.

[39] Nash, J. Sparking up-smoking and style in school. Health Education Journal, 46, 152-155.

[40] Armstrong, B. K., de Klerk, N. H., Shean, R. E., Dunn, D. A. and Dolin, P. J. Influence of education and advertising on the uptake of smoking by children. The Medical Journal of Australia, 152, 117-124.

[41] Telch, M. J., Miller, L. M., Killen, J. D., Cooke, S. and Maccoby, N. (1990) Social influences approach to smoking prevention: the effects of a video tape delivery with and without same age peer leader participation. Addictive Behaviours, 15, 21-28.

[42] Wiist, W. H. and Snider, G. Peer education in friendship cliques: prevention of adolescent smoking. Health Education Research, 6, 101-108.

[43] Abernathy, T. J. and Bertrand, D. B. Preventing cigarette smoking among children: results of the four year evaluation of the PAL Programme. Canadian Journal of Public Health, 83, 226-229

[44] Klepp, K. I., Halper, A. and Perry, C. L. The efficacy of peer leaders in drug abuse prevention. Journal of School Health, 56, 407-411

[45] Hansen, W. B. and Graham, J. W. Preventing alcohol, marijuana and cigarette use among adolescents: peer pressure resistance training versus establishing conservative norms. Preventative Medicine, 10, 414-430.

[46] McKegarney, N. and Barnard, B. AIDS, Drugs and Sexual Risk: Lives in the Balance. Open University Press, Buckingham.

[47] Klee, H. and Reid, P. Amphetamine-Misusing Groups: A Feasibility Study of the Use of Peer Group Leaders For Drug Prevention Among Their Associates. Home Office Drugs Prevention Initiative, London.

[48] Fitzgerald, K 2003, 'Drug education is REDI for a change', Of Substance: the national magazine on alcohol, tobacco and other drugs, vol. 1, no. 1, p. 20.

[49] Loxley, W, Toumbourou, JW, Stockwell, T, Haines, B, Scott, K, Godfrey, C, Waters, E, Patton, G, Fordham, R, Gray, D, Marshall, J, Ryder, D, Saggers, S, Sanci, L \& Williams, J . The prevention of substance use, risk and harm in Australia: a review of the evidence, The National Drug Research Centre and the Centre for Adolescent Health, n. p.

[50] Sheehan K, DiCara JA, LeBailly S, Christoffel KK: Adapting the gang model: peer mentoring for violence prevention. Pediatrics 1999, 104:5054.

[51] Perry, C. L. and Sieving, R. Peer Involvement in Global AIDS Prevention among Adolescents. University of Minnesota/World Health Organisation.

[52] HEA . Peers in Partnership: HIV/AIDS Education with Young People in the Community. Health Education Authority, London.

[53] Rhodes, T. HIV outreach, peer education and community change: developments and dilemmas. Health Education Journal, 53, 92-99.

[54] Broadhead $\mathrm{R}$ et al.The impact results of a peer-driven intervention to combat HIVamong drug injectors. XII International Conference on AIDS, Geneva, 1998.

[55] Ott MA, Evans NL, Halpern-Felsher BL, Eyre SL: Differences in altruistic roles and HIV risk perception among staff, peer educators, and 
students in an adolescent peer education program. AIDS Educ Prev 2003 15:159-171.

[56] McDonald, J, Roche, AM, Durbridge, M \& Skinner, N 2003, Peer education: from evidence to practice, National Centre for Education and Training on Addiction, Adelaide.

[57] Neal RE, Ajamie LF, Harmon KD, Kellerby CD, Schweikhard AJ.Peer Education in the Commons: A New Approach to Reference Services.Med Ref Serv Q. 2010 Oct;29(4):405-13.

[58] A Method in Prevention of Cancer: Peer Education.Asian Pacific J Cancer Prev, 8, 628-630.

[59] Hailey B J, Lalor K M, Byrne HA, et al (1992). The effects of selfreinforcement and peer reinforcement on the practice of breast selfexamination. Hlth Educ Res, 7, 165-74.

[60] Weinrich SP, Boyd MD, Weinrich M, et al. Increasing prostate cancer screening in African American men with Peer-Educator and ClientNavigator interventions. J Cancer Educ, 13, 213-9.

[61] Fork HE, Wagner RF, Wagner KD. The Texas Peer Education Sun Awareness Project for Children: primary prevention of malignant melanoma and nonmelanocytic skin cancers. Cutis, 50, 363-4.

[62] Reding DJ, Fischer V, Gunderson P. Skin cancer prevention: a peer education model. Wis Med J, 94, 77-81.

[63] Lierman LM,Young HM, Powel-Cope G, et al.Effects of Education and Support on Breast Self-Examination in Older Women. Nursing Research, 43,158-63.

[64] Tuna A, Dicle A. The Effect Of Peer Education Model for Teaching Breast Self Examintion To Female Undergraduatuate Students. The First Regional Meeting OfThe Asian Pacific Organization For Cancer Pervention, Ege Universitesi MOTBE BE Salonu, Izmir, 14-16/10/2003.

[65] Sevil U, Atan S U, Kiris H. Peer education project on breast selfexamination in Izmir,Turkey. Asian Pacific J Cancer Prev, 6, 29-32.

[66] Anderson BJ, Wolf FM, Burkhart MT, Cornell RG, Bacon GE: Effects of peer-group intervention on metabolic control of adolescents with IDDM. Randomized outpatient study.Diabetes Care 1989, 12:179-183.

[67] Greco P, Pendley JS, McDonell K, Reeves G: A peer group intervention for adolescents with type 1 diabetes and their best friends. J Pediatr Psychol 2001, 26:485-490.
[68] JA Euyoque.Effects of a peer-led educational intervention on support resources, self-effcacy, depression, beliefs, and self-management behaviors in Latinos with Type 2 diabetes .(unpublished)

[69] Greco P, Pendley JS, McDonell K, Reeves G: A peer group intervention for adolescents with type 1 diabetes and their best friends. J Pediatr Psychol 2001, 26:485-490.

[70] Amireh Ghorob,Maria M Vivas,Diana De Vore, et al.The effectiveness of peer healthcoaching in improving glycemic control among lowincome patients with diabetes:protocol for a randomized controlled trial. Public Health Nursing . 2011.

[71] Baghianimoghadam MH, Hadavandkhani M, Mohammadi M, Fallahzade H, Baghianimoghadam B Current education versus peereducation on walking in type 2 diabetic patients based on Health Belief Model: a randomized control trial study. Rom J Intern Med. 2012 AprJun;50(2):165-72.

[72] Reijneveld S.A.. Promotion of health and physical activity improves the mental health of elderly immigrants: results of a group randomized controlled trial among Turkish immigrants in the Netherland aged 45 and over. J Epidemiol Community Health.57: 405-411.

[73] Nancy Wells Chris Pasero Margo Mccaffery Chapter 17. Improving the Quality of Care Through Pain Assessment and Management.

[74] Riley RR,Witkop M,Hellman E,AK.assessment and management of pain in hemophilia patients.Haemophilia,2011;(17):839-845.

[75] Linda C. Baumann PhD, ANP-BC, FAAN Thanh Tran Ngoc Dang MS, RN.Helping patients with chronic conditions overcome barriers to selfcare.The Nurse Practitioner: The American Journal of Primary Health Care. 2012,(37):32 - 38.

[76] Funnell MM.Peer based behavioural strategies to improve chronic disease self-management and clinical outcomes: evidence, logistics, evaluation considerations and needs for future research. Fam Pract. 2010;27(suppl 1):i17-i22.

[77] Laura B Allen, Jennie CI Tsao, Loran P Hayes, Lonnie K Zeltzer."Peer mentorship to promote effective pain management in adolescents: study protocol for a randomised controlled trial," Trials, vol. 12, no. 1, pp. 132, 2011. 